NBER WORKING PAPER SERIES

\title{
PRODUCT DEVELOPMENT AND THE TIMING OF INFORMATION DISCLOSURE UNDER U.S. AND \\ JAPANESE PATENT SYSTEMS
}

\section{Reiko Aoki}

Thomas J. Prusa

Working Paper No. 5063

\section{NATIONAL BUREAU OF ECONOMIC RESEARCH 1050 Massachusetts Avenue \\ Cambridge, MA 02138 March 1995}

We gratefully acknowledge the financial support of the Japan Foundation Center for Global Partnership and the Suntory Foundation. Aoki thanks the Institute for Social and Economic Research at Osaka University for their hospitality where preliminary work on this paper was done. We would like to thank John Hillas, and Akio Sakai. Thanks are also due to Shoji Saigo and Sukenori Nojo of the Japanese Patent Office. This paper is part of NBER's research program in International Trade and Investment. Any opinions expressed are those of the authors and not those of the National Bureau of Economic Research.

(C) 1995 by Reiko Aoki and Thomas J. Prusa. All rights reserved. Short sections of text, not to exceed two paragraphs, may be quoted without explicit permission provided that full credit, including $\odot$ notice, is given to the source. 


\title{
PRODUCT DEVELOPMENT AND THE TIMING OF INFORMATION DISCLOSURE UNDER U.S. AND \\ JAPANESE PATENT SYSTEMS
}

\begin{abstract}
This paper examines the consequences of the differences in the timing of information disclosure between the U.S. and Japanese patent systems. Under the Japanese system it is possible for a firm to apply for a patent knowing the exact specifications of a rival's patent application. In contrast, in the U.S. the only way a firm learns about a rival's innovation is upon the actual granting of the rival's patent. We argue that this difference enables Japanese firms to coordinate their R\&D efforts better than their U.S. counterparts and that this, in turn, leads to smaller quality improvements under the Japanese system. We show that the creation/diffusion tradeoff of patents can be influenced not only by the scope and length of patent protection but also by other features of the patenting process.
\end{abstract}

Reiko Aoki

Department of Economics

State University of New York at Stony Brook

Stony Brook, NY 11794-4384
Thomas J. Prusa Department of Economics State University of New York at Stony Brook Stony Brook, NY 11794-4384 and NBER 


\section{INTRODUCTION}

Although the United States is still the world's R\&D leader, concerns have grown over the quality, quantity, and content of U.S. R\&D, especially in comparison with Japanese R\&D. Particularly noteworthy was the recent National Science Foundation report (1992) that highlighted differences in U.S. and Japanese R\&D patterns and concluded that there were still many important differences in U.S. and Japanese R\&D patterns. Among its many findings, the NSF report suggests that the R\&D of many Japanese firms tend to result in relatively minor or incremental improvements, a result consistent with findings of other empirical studies. ${ }^{1}$

A number of explanations have been put forth for understanding the differences between U.S. and Japanese R\&D-interest rates and tax treatment, antitrust laws, and the nature of government are among the most widely mentioned. However, little attention has been paid to the differences in the intellectual property protection systems of the U.S. and Japan. In a broad sense, the goal of this paper is to begin to address this shortcoming by studying how institutional differences between patent laws can give rise to differences in the R\&D decisions of U.S. and Japanese firms. More narrowly stated, the purpose of this paper is to examine the consequences of differences in the timing of information disclosure between the U.S. and Japanese patent systems.

In particular, we focus on the amount and timing of credible information disclosed during the patent application review process and argue that disclosure can have a significant effect on a rival's $R \& D$ investment. Our argument relies on the fact that the patent examination process takes a significant length of time - often upwards of seven

\footnotetext{
${ }^{1}$ For example, Business Week (1993) reports a recent study by CHI Research that used U.S. patent citations to conclude that R\&D conducted by U.S. firms had the largest "technology impact". The Japanese used the single claim filing until 1975. Some of the patents in the study would date prior to 1975. One could argue that single claim system is responsible for appearance of incremental improvements.
} 
years. In fact, the review process is sufficiently lengthy that a rival firm can develop a competing product during the time the original product is being examined.

Under the Japanese patent system the patent application is publicly disclosed or "laid open" 18 months after the filing date, i.e., the Japanese practice of kokai. All key information contained in the patent application is automatically published in the Patent Gazette. Furthermore, the Patent Office's examination as to the substance of the application normally does not begin until after the public disclosure (Someno and Someno, 1977; Doi, 1988). ${ }^{2}$ By contrast, in the U.S. information contained in a patent application is published in the Official Gazette of the United States Patent and Trademark Office only after the patent has been granted.

We show that this procedural difference leads Japanese firms to make smaller improvements in quality than they would under the U.S. system, and therefore plays a role in explaining observed differences in U.S. and Japanese R\&D. Unlike what is expected from a simple spillover argument, we show a firm is better off if it is able to reveal its information. We also show that consumers and producers differ in their opinion about the quality changes induced by the disclosure rules: industry profits are higher under Japanese rules but consumers prefer the U.S. rules. ${ }^{3}$

Although the main focus of this paper is to analyze the differences in U.S. and Japanese patent systems, our results also relate to existing industrial organization literature on information diffusion and patents. A key difference in our work is the emphasis on

\footnotetext{
${ }^{2}$ Prior to the laying open of the application the patent examiner's typically only verifies whether the application complies with technical formalities, e.g., whether all documents and drawings are complete, whether the appropriate fees have been paid, etc. (Someno and Someno, 1977).

${ }^{3}$ The information disclosure rules of U.S. patent system imply that differences in patent application dates must be quite large before one firm's patent application influences its rival's behavior; therefore, under the U.S. system it is often not sensible to distinguish between the first or second filer. In contrast, in Japan the laying open of the patent application occurs quite early relative to the overall length of the patent review, making the notion of first versus second filer relevant in a wide range of cases.
} 
coordination issues while authors such as Scotchmer and Green (1990), Gallini (1992), and Matutes, Regibeau, and Rockett (1991) emphasize spillover and also on policy characteristics such as length and breadth of protection.

In the next section we sketch a model of vertical quality differentiation. In sections 3 and 4 we characterize equilibria under the two systems. We compare the systems in section 5 . In section 6 we discuss extensions to our model and robustness of our results. We make a few concluding comments in section 7 .

\section{THE MODEL}

Our insight about the important differences in the disclosure rules can be made most simply in a two player R\&D game. We imagine that there are two identical firms, 1 and 2, who compete against one another in a common market. Under either patent system, once the patents are approved, the firms compete for sales, implying that there are two stages of competition between the firms. The first stage involves the R\&D investments (and quality choices) while the second stage involves the firms simultaneously announcing their prices and consumers then deciding which product (if either) to purchase. The model is solved backwards for the subgame perfect equilibrium.

We interpret the differences in the disclosure rules as inducing a different informational structure for the $\mathrm{R} \& \mathrm{D}$ decisions. Figure 1 depicts how the disclosure requirement is interpreted in our model. Without loss of generality, we assume that at time $t_{0}$ firm 1 makes it's quality choice and files for patent protection. After an initial review period ( $\Delta$ months) information contained in the patent application may or may not be published (at time $t_{1}$ ), depending on the patent system. If firms are competing under the Japanese system, the application is laid open, and firm 2 who is still developing its 
product can adjust its $\mathrm{R} \& \mathrm{D}$ to better compete against firm 1's quality. In contrast, if firms are competing under the U.S. system, the information in firm 1's patent application is not published, implying that firm 2 still does not know firm 1's quality. We assume that under either system at time $t_{2}$, firm 2 finalizes its quality choice and files for patent protection. Finally, after the (typically) lengthy patent review process both firms receive patents and compete against one another on the market (time $\left.t_{4}\right)$. Thus, the Japanese practice of laying open patent applications leads to a sequential quality investment game while the U.S. patent system induces a simultaneous quality choice game.

Before proceeding to solving the model, we note two assumptions that are implicit in the model. First, it is conceivable that due to the differences in the filing dates the firms might receive their patents sequentially and thus reach the product market sequentially. This potential difference in the time the products reach the market will be insignificant as long as the length of time that both products are patented is relatively large as compared with the time that only one of the products is available, as we assume

is the case. Second, we assume that profit will be zero if a firm fails to innovate. In general, a firm would have an existing product that it could sell if it does not engage in $R \& D$. Thus, our model should be interpreted as capturing $R \& D$ incentives in a new market.

\section{Equilibrium of the Second Stage}

In a model with vertically differentiated quality, given two products of different qualities sold at the same price, all consumers unambiguously rank one quality as being better 
than the other. ${ }^{4}$ Suppose, for example, the product we are considering are automobiles and the quality dimension is safety; all consumers agree that a safer automobile is the higher quality (superior) product. In our model, if the same price is charged for both type of autos, then only the safer model will be purchased. It follows that the inferior product, will only be purchased if its price is low enough to compensate for its lower quality. ${ }^{5}$

Therefore, if both high and low quality products have positive sales, consumers must be "heterogeneous", by which we mean the fact that some consumers value quality more than others. In other words, there are differences in consumers' willingness to pay for quality. In order to capture this heterogeneity we assume that there is a continuum of consumers indexed by $\alpha$ which are uniformly distributed over the interval $[0,1]$. Higher $\alpha$ values reflect the consumer's higher valuation of quality. A type $\alpha$ consumer will get a surplus of $v_{\alpha}(q, p)=\alpha q-p$ if he buys one unit of product of quality $q \in[0, \infty)$ at price $p \in[0, \infty)$.

At the second stage, given the available quality and price combinations, a consumer will buy one unit of a product if the surplus is (i) positive and (ii) greater than the surplus from consuming the other product. Given our assumptions one can show that there is an unique pair of equilibrium prices (and quantities sold) associated with each pair of possible qualities, implying that the equilibrium sales revenue can be expressed as functions of quality choices alone. ${ }^{6}$

For simplicity, we assume that there is no cost of second stage production, allowing

\footnotetext{
${ }^{4}$ See Gabszewicz and Thisse (1979), Shaked and Sutton (1982), and Aoki (1988) for more detailed discussions of vertical quality differentiation.

${ }^{5}$ This contrasts to a model with horizontally differentiated products, where each consumer has a most preferred quality which implies, in general, that different consumers prefer different products. An example of horizontal quality differentiation is automobiles with different colors.

${ }^{6}$ All proofs are available upon request.
} 
us to write the revenue for firm $1, R_{1}\left(q_{1}, q_{2}\right)$, as

$$
R_{1}\left(q_{1}, q_{2}\right)= \begin{cases}\frac{4\left(q_{1}\right)^{2}\left(q_{1}-q_{2}\right)}{\left(4 q_{1}-q_{2}\right)^{2}}, & \text { if } q_{1} \geq q_{2} \\ \frac{q_{2} q_{1}\left(q_{2}-q_{1}\right)}{\left(4 q_{2}-q_{1}\right)^{2}}, & \text { if } q_{1}<q_{2}\end{cases}
$$

Firm 2's revenue, $R_{2}\left(q_{1}, q_{2}\right)$, can be defined analogously. From (1) it follows that the revenue functions, $R_{1}\left(q_{1}, q_{2}\right)$ and $R_{2}\left(q_{1}, q_{2}\right)$, are continuous at any $\left(q_{1}, q_{2}\right)$ and are differentiable at all points except at $q_{1}=q_{2}$. Note that if the quality of the two firms are identical $\left(q_{1}=q_{2}\right)$, both firms' sales revenues will be zero.

Firm 1's revenue function is depicted in the upper-panel of Figure 2. Notice that firm 1's revenue depends on firm 2's quality choice. When firm 2's quality is $q_{2}$, firm 1's revenue is depicted by the solid revenue line; the dashed revenue line depicts firm 1's revenue when firm 2's quality is slightly larger, say $q_{2}^{\prime}$.

The shape of the revenue function warrants several comments. First, suppose that firm 2 chooses $q_{2}$ and firm 1 is the high quality firm. In this case, note that firm 1's revenue increases when the distance between the qualities is increased. The greater distance could be due to an increase in its own quality or to a reduction in the rival's quality. On the other hand, if the distance between the qualities narrows (for example when firm 2 slightly increases its quality to $q_{2}^{\prime}$ ), firm 1's revenue falls (the revenue function shifts down to the dashed line).

Second, continue to assume that firm 2 chooses quality $q_{2}$ but now imagine that firm 1 is the low quality firm. In this case, firm 1 benefits when firm 2 improves its quality. For example, if firm 2 moves from $q_{2}$ to $q_{2}^{\prime}$, firm 1's revenue function shifts up. However, firm 1's revenue does not necessarily increase when the distance between qualities increases due to a decrease in its own quality. Rather, firm 1 prefers to maintain 
an optimal distance from firm 2's quality. In the diagram this "optimal distance" quality is depicted as $\bar{q}\left(q_{2}\right)$. This is because the low quality firm faces two margins: one with respect to the high quality good and one with respect to the outside good (i.e., no sale). If firm 1 raises its quality any higher than $\bar{q}\left(q_{2}\right)$, the products become too similar and competition reduces revenue. On the other hand, firm 1 does not want its quality to be too low, in order to avoid losing customers to the outside good.

Third, the revenue functions are also characterized by some important second-order effects. In particular, the firms' revenue functions are locally concave in their own quality. Formally,

$$
\frac{\partial^{2} R_{i}\left(q_{1}, q_{2}\right)}{\partial q_{i}{ }^{2}}<0, \text { for } q_{1} \neq q_{2}, i=1,2
$$

In addition, the farther apart are the firms' qualities, the smaller is the effect of changes in the rival's quality choice. Formally,

$$
\frac{\partial^{2} R_{i}\left(q_{1}, q_{2}\right)}{\partial q_{1} \partial q_{2}}>0, \quad \forall\left(q_{1}, q_{2}\right), i=1,2
$$

\section{Characterization of Optimal Quality Choice}

Now that we have characterized how second stage sales revenue is determined, we can proceed to examine the first stage incentives. The profit from the first stage, $\Pi_{i}\left(q_{1}, q_{2}\right)$, consists of revenue from the second stage less the cost of $R \& D$ investment. We will assume that firm $i, i=1,2$, incurs a R\&D cost, $C\left(q_{i}\right)$, to develop quality $q_{i}$. We scale the quality index so $q_{i}=0$ corresponds to "no improvement" or the status quo. For convenience, we will assume that the R\&D cost function has the particular form $C\left(q_{i}\right)=k q_{i}{ }^{2}, k>0$, where $k$ is interpreted as an efficiency parameter. In other words, 
higher values of $k$ correspond to firms that are less efficient at R\&D. This cost function implies that better quality is more expensive and is increasingly so. ${ }^{7}$ In the first stage, each firm will choose quality to maximize $\Pi_{i}\left(q_{1}, q_{2}\right)$, where

$$
\Pi_{i}\left(q_{1}, q_{2}\right)=R_{i}\left(q_{1}, q_{2}\right)-C\left(q_{i}\right)
$$

The lower-panel of Figure 2 depicts the profit functions associated with the revenue functions that are depicted in the upper-panel. Note that the assumptions made on revenue and cost functions guarantee that this profit function is locally concave and that an optimal choice will always exist and will be an interior solution. Therefore, firm $i$ 's best-response correspondence, $q_{i}=\beta_{i}\left(q_{j}\right)$, is characterized by the first-order condition

$$
\frac{\partial \Pi_{i}\left(q_{1}, q_{2}\right)}{\partial q_{i}}=\frac{\partial R_{i}\left(q_{1}, q_{2}\right)}{\partial q_{i}}-C^{\prime}\left(q_{i}\right)=0
$$

As depicted in Figure 2 there are always two local maximums, one below and one above the rival's quality level, denoted by $q^{L}\left(q_{2}\right)$ and $q^{H}\left(q_{2}\right)$, respectively. Whether firm 1 chooses to sell the low or high product depends crucially on what firm 2's quality will be. For instance, the solid line depicts the profit function when firm 2 has chosen quality $q_{2}$; in this case, firm 1 earns greater profit selling the high quality product (the solid line profit function reaches its global maximum at $q^{H}\left(q_{2}\right)$ ). On the other hand, the dashed line depicts the relevant profit function when firm 2 chooses a higher quality $q_{2}^{\prime}$, and firm 1 earns greater profit selling the low quality product (the dashed line profit function reaches its global maximum at $\left.q^{L}\left(q_{2}^{\prime}\right)\right)$.

Clearly, firm 2's quality choice influences whether firm 1 is the high or low quality

\footnotetext{
${ }^{7}$ The specific functional form chosen is not necessary for the existence of pure strategy Nash equilibria but does allow us to derive analytical solutions. We will discuss the robustness of our results in section 6 .
} 
firm. It can be shown that there is a unique quality choice where firm 1 earns the same profit at the two local maxima and therefore is indifferent between being the low or high quality firm. Let $\hat{q}$ denote this quality, i.e. ${ }^{8}$

$$
\Pi_{1}\left(q^{L}(\hat{q}), \hat{q}\right)=\Pi_{1}\left(q^{H}(\hat{q}), \hat{q}\right)
$$

If the firm 2's quality is below this cut-off, $q_{2}<\hat{q}$, then $q^{H}\left(q_{2}\right)$ will be the global maximum. If the firm 2's quality is greater than $\hat{q}$, then $q^{L}\left(q_{2}\right)$ will be the global maximum. This discussion implies that the best-response correspondences, $\beta_{1}\left(q_{2}\right)$ and $\beta_{2}\left(q_{1}\right)$, are discontinuous at $\hat{q}$.

Figure 3 depicts firm 1 's best-response correspondence. Note that for $q_{2}<\hat{q}, \beta_{1}\left(q_{2}\right)$ is above the 45 degree line (i.e., firm 1 is the high quality firm), while for $q_{2}<\hat{q}$, firm 1 is the low quality firm. Note also that $\beta_{1}$ does not cross the 45 degree line since firms always prefer to sell differentiated products. Finally, note that $\beta_{1}$ is upward sloping, for all $q_{2} \neq \hat{q}$.

We have also depicted some of firm 1's iso-profit $\left(d \Pi_{1}\left(q_{1}, q_{2}\right)=0\right)$ curves in Figure 3. Iso-profit curves close to the 45 degree line correspond to negative profits. Along the 45 degree line we know $R_{1}(q, q)=0$ and $C(q)>0, \forall q>0$. For example, consider when firm 2 sells quality $\tilde{q}$. Point $G$ reflects the point where firm 1 also sells quality $\tilde{q}$; at point $G$ each firm earns profit of $-C(\tilde{q})$. Firm 1's profit increases as it moves up vertically from $G$ until its first-order condition is satisfied. Raising quality beyond that point decreases profit. Similarly, firm 1's profit increases as it moves down vertically from $G$ until the first-order condition is satisfied (which is on the best-response correspondence since $\tilde{q}>\hat{q}$ ) and decreases thereafter.

\footnotetext{
${ }^{8}$ Since the firms are identical, $\hat{q}$ can be defined analogously for firm 2 's profit.
} 
In addition, the direction of increasing firm 1's profit along its best-response correspondence is denoted. Along the upper segment of the best-response correspondence profit increases as we move to the southwest. In other words, if firm 1 sells the higher quality product, profits increase the lower is firm 2's quality. In the limit, $q_{2}=0$, and firm 1 has a monopoly. On the other hand, along the lower segment of the bestresponse correspondence profit increases as we move to the northeast. In other words, when firm 1 sells the lower quality product, profits increase the greater is its rival's quality. In the limit, firm 2's quality becomes so large that only those consumers with the highest marginal willingness to pay can afford the superior product, leaving the vast majority of consumers to firm 1 (i.e., firm 1 virtually has a monopoly).

\section{Equilibria Under U.S. Patent Rules}

We begin by solving for the optimal quality choices assuming the disclosure rules defined by the U.S. patent system are in effect. By graphing both firms' best-response correspondences $\beta_{i}\left(q_{j}\right), i=1,2$ we can solve for the Nash equilibria in the game with simultaneous quality choices (Figure 4). A pure strategy Nash equilibrium will be the intersection of the best-response correspondences. There are two pure strategy equilibria, one involving $q_{1}>q_{2}$ and the other with $q_{2}>q_{1}$. The two equilibria are symmetric. ${ }^{9}$ We will refer to the equilibrium involving $q_{i}>q_{j}$ as $E_{i}^{U}$. In addition, one can show that of the two possible Nash equilibria under the U.S. disclosure rules, each firm prefers the equilibrium where it sells the high quality product. In other words, firm $i$ earns greater profit at the equilibrium $E_{i}^{U}$. This is due to the fact that the firm supplying the superior product services the consumers with high marginal willingness to pay, and

\footnotetext{
${ }^{9}$ The quality pairs are the same in both equilibria, only the identity of the firm supplying the high quality product changes.
} 
therefore is able to charge a higher price for its product. We summarize this discussion with the following proposition.

Proposition 1 Under the U.S. patent system, there are two symmetric equilibria. In each equilibrium, the firm selling the superior product earns greater profit than the firm selling the inferior quality product.

\section{Equilibrium Under Japanese Patent Rules}

We now consider the optimal quality choices of the game with sequential quality choice which corresponds to the Japanese patent system. Without loss of generality, assume firm 1 files its patent application first and the application is laid open before firm 2 makes its own quality choice. With this information structure, firm 2's R\&D level should maximize its profit given that it observes firm 1's choice. That is, firm 2's choice should satisfy the best-response correspondence, $q_{2}=\beta_{2}\left(q_{1}\right)$. Firm 1 maximizes its profit by choosing the quality corresponding to the highest iso-profit curve along firm 2's best-response curve.

In Figure 4, for $q_{1}>q_{2}$, firm 1 achieves higher profit by moving southwest from $E_{1}^{U}$ along $q_{2}=\beta_{2}\left(q_{1}\right)$ to the point $E^{J}$. At $E^{J}$ firm 1's iso-profit curve is tangent to firm 2's best-response correspondence. For $q_{1}<q_{2}$, firm 1 achieves higher profit by moving northeast from $E_{2}^{U}$ along $q_{2}=\beta_{2}\left(q_{1}\right)$ to the point $F .{ }^{10}$

Note that $F$ and $E^{J}$ are only local maxima for firm 1 ; however, as was the case under U.S. rules, firm 1 prefers to sell the high quality product. In other words, $E^{J}$ is the global maximum. This discussion can be summarized as

\footnotetext{
${ }^{10}$ Of course, either $F$ or $E^{J}$ could occur at the "kink" of $\beta_{2}\left(q_{1}\right)$. Our results do not depend on the tangency of the solution.
} 
PROPOSITION 2 Let firm 1 be the first firm to file for patent protection. Under the Japanese patent system, there is one equilibrium, $E^{J}$.

\section{Comparing Equilibria Under U.S. and JaPanese Patent Systems}

We begin by comparing the set of qualities offered at the Japanese equilibrium, $E^{J}$, and firm 1's preferred U.S. equilibrium, $E_{1}^{U}$. Since the two U.S. equilibria are symmetric, the set of qualities available to consumers is the same at $E_{1}^{U}$ and $E_{2}^{U}$. From the consumers' viewpoint, all that is relevant is the pair of qualities offered, not the identity of the firms

supplying the qualities, which implies that the two U.S. equilibria are equivalent. In light of this equivalence, we will find it convenient to focus on the qualities offered at $E_{1}^{U}$, i.e., when firm 1 supplies the superior product.

Along firm 1's best response correspondence, $E^{J}$ lies to the northeast of $E_{1}^{U}$, implying that the Japanese practice of laying open the patent application leads firm 1 to choose a quality level lower than it would if its information was not revealed. Moreover, this lower quality induces the rival to also choose a lower quality.

In other words,

PROPOSITION 3 The qualities offered under Japanese rules are lower pair-wise than the qualities offered under U.S. patent rules.

The intuition for this result is that first filer uses the laying open of its application to influence its rivals quality choice. Because the second firm prefers to avoid directly competing with firm 1's pre-existing patent application, it will adjust its quality choice accordingly. Since the best-response correspondences are upward sloping, firm 1 takes advantage of the disclosure requirement to supply a lower quality than it would if its information were not revealed. 
Because we emphasize the coordination aspect of the disclosure requirement, rather than spillover issues, our model also implies that firm 1 benefits from this information revelation.

PROPOSITION 4 The firm supplying the superior product earns greater profit under Japanese rules while the firm supplying the inferior product earns greater profit under U.S. rules.

It can be argued, however, that policy-maker's are more concerned with industry profit than how individual firms fare. This may be particularly true in Japan where it is widely held that institutions and practices are aimed toward facilitating joint-profit maximizing behavior, e.g., the distribution system, the prevalence of retail price maintenance arrangements, exclusive dealerships, antitrust laws, etc. We find that Japanese disclosure rules are consistent with Japanese institutions/laws that are believed to facilitate joint-profit maximizing behavior. Specifically, we can numerically show that

Proposition 5 Aggregate profit is greater under Japanese patent rules than under U.S. patent rules.

The different disclosure rules may also affect consumers' well-being. Although consumers prefer superior quality products (holding price constant) the lower qualities offered under Japanese rules may entail sufficient price competition at the second stage that consumers' welfare may increase. However, we can show that qualities offered by the firms are sufficiently different that consumers' desire for superior products is the primary effect, and therefore that

Proposition 6 Consumers' surplus is greater under U.S. patent rules than under Japanese patent rules. 
Taking propositions 5 and 6 together, it becomes clear that the Japanese disclosure rules have the effect of benefiting producers at the expense of consumers. Again, this finding is consistent with other aspects of the Japanese economy that appear to be geared toward maximizing producer surplus.

Finally, we can calculate the overall effect of the disclosure rules. Defining social surplus as the sum of profits and consumer surplus, we can numerically show that

Proposition 7 Social surplus is greater under U.S. patent rules than under Japanese patent rules.

In other words, the benefit to producers from the Japanese practice of laying open patent applications is outweighed by the loss to consumers. In fact, the loss to consumers is an order of magnitude larger than the benefit to producers.

\section{Extensions and Robustness}

Above we have shown that the laying open of patent applications lowers quality choices, raises industry profit, and lowers consumer surplus. Below we examine the robustness of these conclusions to alternative assumptions on preferences and technology. We also examine consequences of extensions to the basic model.

Strategic Complementarity of the Revenue Function An important property is the strategic complementarity of the revenue function. ${ }^{11}$ This property gives rise to the upward sloping best-response correspondence. With the upward sloping best-response correspondences, under Japanese rules the first filer will always choose a lower quality than it would under U.S. rules.

\footnotetext{
${ }^{11}$ Technically, this is equivalent to the cross derivative being positive.
} 
While strategic complementarity is a general condition that arises in many $R \& D$ models, in our model it arises from the assumptions that firms choose prices in the second stage and that the products are substitutes. Consider relaxing each of these assumptions. First, the same demand system can allow quantities to be chosen at the second stage. As shown in Aoki (1994), quantity competition results in one segment of the best-response correspondence being downward sloping and the other upward sloping. In this case, the first filer chooses a quality higher than under U.S. rules, but the second filer still chooses a lower quality.

Second, it is possible to have demand systems where products are complements. In that case, disclosure rules could facilitate both firms to engage in either more or less $R \& D$ depending upon the nature of the complementarity and on whether there is price or quantity competition.

R\&D Technology Another key property is the fact that the cost of R\&D does not increase too quickly. This implies that of the two local optima under Japanese rules, the equilibrium is the one where the first filer produces the higher quality product. Thus, we conclude that in comparison with U.S. rules, a inferior pair of qualities is offered under Japanese rules. Note that the other local optima involves the first filer choosing the lower quality; this could be the equilibrium if cost increased very rapidly. If this were the Japanese optimum (point $F$ in Figure 4) then Japanese patent rules would result in a superior pair of qualities as compared to U.S. rules. Therefore, the fact that cost does not increase too quickly is crucial.

We stress, however, that the situation that we have modeled (i.e., where cost does not increase too quickly) is in fact the interesting case. If the cost of quality increases very quickly - and therefore quality is very expensive - the effect of different patent systems 
would be minimal since firms would choose to make very small $R \& D$ investments under either system. Therefore, the insights of this paper are most appropriate for situations when the cost of quality is small or rises relatively slowly.

R\&D Choice vs. Filing Choice We have assumed throughout this paper that firm's truthfully represent their $R \& D$ quality in their patent application. However, firms may have incentives to strategically over- or under-represent their true quality. The fact that the applications are carefully examined by the patent office, makes it plausible to assume that over-representation of quality is not possible.

On the other hand, a firm may have an incentive to under-represent its quality in order to induce the rival to choose even lower quality. By actually producing product with the true quality, a firm is able to attain higher profit than it would have had the rival reacted to the true higher quality. However, the patent protection will only be for claimed lower (under-represented) quality. It is questionable that even after accounting for the scope of protection, the true (better) quality is protected. If it is not protected, then as long as imitation is not too costly, profits will be driven to zero if products are sold with the true quality but patented at a lower claimed quality. Thus, we conclude that the incentives for a firm to under-represent its true quality is limited.

Determination of First Filer The determination of the leader and follower have been left exogenous in our formulation. Our model may be extended by adding an additional stage at the beginning of the game to address this question. One may consider a situation such as the patent race analyzed by Reinganum (1982). She has shown, in a dynamic game framework, that the research intensity of firms in this additional stage will be increasing in the winner's profit and decreasing in the loser's profit. In our 
context, the winner is the first filer and the loser is the follower.

This result and our proposition 4, imply that the research intensity will be greater under the Japanese patent system than under the U.S. system. Thus there is the possibility that any gain in profits under the Japanese system is actually competed away in the race to be the first filer. Unfortunately, it is impossible to determine analytically how the expected equilibrium payoff of the patent race game depends on winner and loser profits. A numerical analysis shows that in fact this rent dissipation does not occur. That is, expected equilibrium payoff of the patent race is larger with profits under the Japanese system than with profits under the U.S. system. Thus, even taking into account the expenditures incurred during the race to be the first filer, firms find the Japanese system more attractive. In addition, greater research intensity means that the expected date of success is earlier under the Japanese system.

By simply applying Reinganum's results to our model, we are assuming there is no relationship between the research expenditure in the patent race stage and the ability to develop a higher quality product. It is possible that some relationship exists. For instance, superior research might imply lower cost of development. Analysis of a model which takes this into account is certainly an interesting one and we have left it for future research.

\section{Concluding Comments}

We have shown that the disclosure requirements of the Japanese patent system result in lower quality offerings than under the U.S. patent rules. We have argued that the Japanese practice of laying open patent application is another example of the information disseminating emphasis of the Japanese patent system. We have focused on an 
aspect of patent policy other than the traditional breadth and length.

We have also focused on the coordination aspect of information dissemination. Previous research has emphasized other aspects of the Japanese patent system's propensity for information revelation. For instance, Ordover (1991) emphasizes aspects of the Japanese system that induce information sharing via licensing, cross-licensing and joint R\&D ventures. Scotchmer and Green (1990) compare the Japanese "first-to-file" priority rule with the U.S.'s "first-to-invent" and find that Japanese priority rules lead to more disclosure. However, this earlier research focuses on the amount of information disclosed under the alternative systems while we focus on the timing of disclosure.

Although it has not been formally analyzed in this paper, the Japanese patent system may have important implications for concerns over spillover. As discussed earlier, spillover would also result in the first filer reducing its quality. However, spillover would not cause the profit of the first filer to increase. In addition, very specific assumptions on the $R \& D$ efficiency of the two firms would be required in order for the aggregate profit to increase with spillover. Our discussion suggests that information revelation has two effects: spillover and coordination. Which effect dominates is difficult to assess, but the fact that U.S. firms strongly backed the recent GATT accord which incorporates the laying open of patent applications is consistent with the belief that firms prefer information dissemination. In addition, this valuable coordination device cannot be duplicated by U.S. firms acting alone. The information disclosure must be truthful and credible. There is no such guarantee if the revelation is simply voluntary, since firms may have an incentive to misrepresent their true quality. However, information revealed through the laying open is credible since the government announces the actual patent application. 


\section{REFERENCES}

Aoki, Reiko, "Cournot and Bertrand Competition with Vertical Quality Differentiation", mimeo (1988).

Aoki, Reiko, "Sequential vs. Simultaneous Quality Choices with Bertrand and Cournot Competition", mimeo (1994).

"Global Innovation: Who's in the Lead?" Business Week, August 3, 1992.

Doi, Teruo, editor. "Intellectual Property", in Japanese Business Law Guide (1988) CCH International: Sydney, Australia.

Gabszewicz, J. and J.-F. Thisse, "Price Competition, Quality and Income Distribution", Journal of Economic Theory 20 (1979) 340-359.

Gallini, Nancy T., "Patent Policy and Costly Imitation", Rand Journal of Economics 23 (1992) 1-19.

Matutes, Carmen, Pierre Regibeau, and Katharine Rockett, "Optimal Patent Design and the Diffusion of Innovations", J.L. Kellog Graduate School of Management Discussion Paper No. 91-39 (1992).

National Science Board, The Competitive Strength of U.S. Industrial Science and Technology (1992) National Science Foundation: Washington, D.C.

Ordover, Janusz A., "A Patent System for Both Diffusion and Exclusion", Journal of Economic Perspectives 5 (1991) 43-60.

Reinganum, Jennifer. F., "A Dynamic Game of R and D: Patent Protection and Competitive Behavior", Econometrica 50 (1982) 671-688.

Scotchmer, Suzanne and Jerry Green, "Novelty and Disclosure in Patent Law", Rand Journal of Economics 21 (1990) 131-146.

Shaked, A., and J. Sutton, "Relaxing price competition through product differentiation", Review of Economic Studies 49 (1982) 3-13,

Someno, Yoshinobu and Keiko Someno, "Patent Office and Court Procedures in Japan" in Teruo Doi and Warren L. Shattuck, eds. Patent and Know-How Licensing in Japan and the United States (1977) University of Washington Press: Seattle. 


\section{APPENDIX}

\section{Characteristics of the firms' revenue functions}

A type $\alpha$ consumer will purchase the lower quality product, $q^{L}$, if

$$
0 \leq v_{\alpha}\left(q^{L}, p^{L}\right)>v_{\alpha}\left(q^{H}, p^{H}\right)
$$

and will purchase the higher quality product, $q^{H}$, if

$$
0 \leq v_{\alpha}\left(q^{H}, p^{H}\right)>v_{t}\left(q^{L}, p^{L}\right)
$$

Clearly, if both types of products are bought, the higher quality product is purchased by consumers with high willingness to pay (larger $\alpha$ ) since $v_{\alpha}(\cdot)$ is increasing in $\alpha$.

There is an unique pair of equilibrium prices associated with each pair of possible qualities, $q^{H} \geq q^{L}$. In particular, using the above relations the equilibrium demand, $x^{H}$ and $x^{L}$, and prices, $p^{H}$ and $p^{L}$, can be expressed as

$$
\begin{aligned}
x^{H}\left(q^{H}, q^{L}\right) & =\frac{2 q^{H}}{4 q^{H}-q^{L}}, & p^{H}\left(q^{H}, q^{L}\right) & =\frac{2 q^{H}\left(q^{H}-q^{L}\right)}{4 q^{H}-q^{L}} \\
x^{L}\left(q^{H}, q^{L}\right) & =\frac{q^{H}}{4 q^{H}-q^{L}}, & p^{L}\left(q^{H}, q^{L}\right) & =\frac{q^{L}\left(q^{H}-q^{L}\right)}{4 q^{H}-q^{L}} .
\end{aligned}
$$

Given these expressions, the equilibrium sales revenue (for the second stage) for the high and low quality firms can be expressed as functions of quality choices alone,

$$
\begin{aligned}
& r^{H}\left(q^{H}, q^{L}\right)=\frac{4\left(q^{H}\right)^{2}\left(q^{H}-q^{L}\right)}{\left(4 q^{H}-q^{L}\right)^{2}} \\
& r^{L}\left(q^{H}, q^{L}\right)=\frac{q^{H} q^{L}\left(q^{H}-q^{L}\right)}{\left(4 q^{H}-q^{L}\right)^{2}}
\end{aligned}
$$


If we assume that firm 1 supplies the high quality product, then (A.3) and (A.4) can be used to derive (1).

The important properties of the revenue function which we discussed in the paper can be summarized with the following equations.

When $q_{i}>q_{j}$

$$
\begin{gathered}
\frac{\partial R_{i}\left(q_{1}, q_{2}\right)}{\partial q_{i}}>0 \text { and } \frac{\partial R_{i}\left(q_{1}, q_{2}\right)}{\partial q_{j}}<0, \\
\frac{\partial R_{j}\left(q_{1}, q_{2}\right)}{\partial q_{i}}>0, \\
\frac{\partial R_{j}\left(q_{1}, q_{2}\right)}{\partial q_{j}} \gtreqless 0 \Leftrightarrow q_{j} \lesseqgtr \bar{q}, \quad \text { where } \bar{q}=(4 / 7) q_{i} .
\end{gathered}
$$

And, for all $q_{1}, q_{2}$

$$
\begin{array}{r}
\frac{\partial^{2} R_{i}\left(q_{1}, q_{2}\right)}{\partial{q_{i}}^{2}}<0, \text { for } q_{1} \neq q_{2}, i=1,2 \\
\frac{\partial^{2} R_{i}\left(q_{1}, q_{2}\right)}{\partial q_{1} \partial q_{2}}>0, \quad \forall\left(q_{1}, q_{2}\right)
\end{array}
$$

\section{Characteristics of the firms' best-response correspondences}

As depicted in Figure 2 there are always two local maximums, one below and one above the rival's quality level, denoted by $q^{L}\left(q_{j}\right)$ and $q^{H}\left(q_{j}\right)$, respectively. Differentiating the profit function, (4), we can define these locally optimal choices as

$$
\begin{aligned}
& q^{L}\left(q_{j}\right)=\left\{q_{i} \in \mathbb{R} \mid q_{j}^{2}\left(4 q_{j}-7 q_{i}\right)-2 k q_{i}\left(4 q_{j}-q_{i}\right)^{3}=0, q_{i}<q_{j}\right\} \\
& q^{H}\left(q_{j}\right)=\left\{q_{i} \in \mathbb{R} \mid 16{q_{i}}^{2}-12 q_{i} q_{j}+8{q_{j}}^{2}-2 k\left(4 q_{i}-q_{j}\right)^{3}=0, q_{i} \geq q_{j}\right\}
\end{aligned}
$$


The best-response correspondence, $\beta_{i}\left(q_{j}\right)$, can be expressed as

$$
\beta_{i}\left(q_{j}\right)= \begin{cases}q^{L}\left(q_{j}\right), & \text { if } q_{j} \geq \hat{q} \\ q^{H}\left(q_{j}\right), & \text { if } q_{1} \leq \hat{q}\end{cases}
$$

where $\hat{q}$ satisfies

$$
\Pi_{1}\left(q^{L}(\hat{q}), \hat{q}\right)=\Pi_{1}\left(q^{H}(\hat{q}), \hat{q}\right)
$$

Proof that firm 1 prefers $E_{1}^{U}$ to $E_{2}^{U}$

Let $q^{H^{*}}=q_{1}^{U_{1}}=q_{2}^{U_{2}}$ and $q^{L^{*}}=q_{2}^{U_{1}}=q_{1}^{U_{2}}$. We show that

$$
\Pi_{1}\left(q^{H *}, q^{L *}\right)>\Pi_{1}\left(q^{L *}, q^{H *}\right)
$$

Given the explicit functional forms of the revenue and cost functions, it is easy to show that $^{12}$

$$
\frac{1}{8 k}<q^{H *}<\frac{7}{48 k}, \quad \frac{1}{64 k}<q^{L *}<\frac{1}{32 k}
$$

From the relation (A.5) and optimality of $q^{H}(\cdot)$, we have the following inequality,

$$
\begin{aligned}
\Pi_{1}\left(q^{H *}, q^{L *}\right) & =\Pi_{1}\left(q^{H}\left(q^{L *}\right), q^{L *}\right)>\Pi_{1}\left(q^{H}\left(\frac{1}{32 k}\right), q^{L *}\right) \\
& >\Pi_{1}\left(q^{H}\left(\frac{1}{32 k}\right), \frac{1}{32 k}\right) \geq \Pi_{1}\left(\frac{1}{8 k}, \frac{1}{32 k}\right)=\frac{53}{4800 k} .
\end{aligned}
$$

\footnotetext{
${ }^{12}$ See Aoki (1994) for details.
} 
Using optimality of $q^{L}(\cdot),(\mathrm{A} .6)$, and (A.7), we find the upper bound of $\Pi_{1}\left(q^{L *}, q^{H *}\right)$.

$$
\begin{aligned}
\Pi_{1}\left(q^{L *}, q^{H *}\right) & <\Pi_{1}\left(q^{L *}, \frac{7}{48 k}\right)<\Pi_{1}\left(q^{L}\left(\frac{7}{48 k}\right), \frac{7}{48 k}\right) \\
& <r^{L}\left(\frac{7}{48 k}, q^{L}\left(\frac{7}{48 k}\right)\right)<r^{L}\left(\frac{7}{48 k}, \frac{1}{32 k}\right)=\frac{77}{44944 k}
\end{aligned}
$$

The last inequality follows from (A.7) and $\frac{1}{32 k}<\frac{4}{7} \frac{7}{48 k}$. From $\frac{53}{4800 k}-\frac{77}{44944 k}>0$ we have inequality (A.13).

\section{Proof that firm 1 prefers $E^{J}$ to $F$}

We show that the payoff for firm 1 at the local optimum $E^{J}=\left(q_{1}^{J}, q_{2}^{J}\right)$ is greater than at the local optimum $F=\left(q_{1}^{F}, q_{2}^{F}\right)$. At $E^{J}$, firm 1 is the higher quality firm while at $F$ it is the lower quality firm, i.e, $q_{1}^{J}>q_{2}^{J}$ and $q_{1}^{F}<q_{2}^{F}$. We will show that

$$
\Pi_{1}\left(q_{1}^{J}, q_{2}^{J}\right)>\Pi_{1}\left(q_{1}^{F}, q_{2}^{F}\right)
$$

By definition of $E^{J}$,

$$
\Pi_{1}\left(q_{1}^{J}, q_{2}^{J}\right)>\Pi_{1}\left(q^{H *}, q^{L *}\right)
$$

Thus the lower bound we attained in (A.15) is also the lower bound for $\Pi_{1}\left(q_{1}^{J}, q_{2}^{J}\right)$.

We will now find the upper bound of $\Pi_{1}\left(q_{1}^{F}, q_{2}^{F}\right)$. First we note that because $F$ is on firm 2's best-response function, $q_{2}^{F}<\frac{7}{48 k}$. Profit at $F$ must be positive for firm 1 and thus the point must lie below the zero iso-profit curve which implies $q_{1}^{F}<\frac{1}{16 k}^{13}$. We are now able to show the following inequalities,

$$
\Pi_{1}\left(q_{1}^{F}, q_{2}^{F}\right)<\Pi_{1}\left(q_{1}^{F}, \frac{7}{48 k}\right)<r^{L}\left(\frac{7}{48 k}, q_{1}^{F}\right)<r^{L}\left(\frac{7}{48 k}, \frac{1}{16 k}\right)=\frac{7}{2500 k} .
$$

\footnotetext{
${ }^{13}$ See Aoki (1994) for details
} 
The first inequality follows from (A.6). The third inequality follows from the fact that $r^{L}(\cdot)$ is increasing in $q^{L}$ for $q_{1}^{F}<\frac{4}{7} \frac{7}{48 k}$ from (A.7). Since $\frac{53}{4800 k}-\frac{7}{2500 k}=\frac{989}{12000 k}>0$, we have shown the inequality (A.18).

\section{Proof that consumer surplus is higher under U.S. Patent Rules}

From the demand system, we can calculate the consumer surplus for any pair of qualities, $\left(q^{H} \geq q^{L}\right)$. Total consumer surplus is the sum of the surplus from those who buy the high quality $\left(C S^{H}\right)$ and from those who buy the lower quality $\left(C S^{L}\right)$,

$$
C S^{H}=\frac{2\left(q^{H}+q^{L}\right)\left(q^{H}\right)^{2}}{\left(4 q^{H}-q^{L}\right)^{2}}, \quad C S^{L}=\frac{q^{L}\left(q^{H}\right)^{2}}{2\left(4 q^{H}-q^{L}\right)^{2}}
$$

The total consumer surplus $(C S)$ is,

$$
C S=\frac{\left(q^{H}\right)^{2}\left(4 q^{H}+5 q^{L}\right)}{2\left(4 q^{H}-q^{L}\right)^{2}}
$$

Differentiating (A.19), we can show that consumer surplus is always increasing in the level of the lower quality,

$$
\frac{\partial C S}{\partial q^{L}}=\frac{\left(q^{H}\right)^{2}\left(28 q^{H}+5 q^{L}\right)}{2\left(4 q^{H}-q^{L}\right)^{3}}>0
$$

An increase in the quality of the inferior product has two beneficial effects on consumer surplus. First, consumers benefit from a better product. Second, there is greater competition between the two products since the qualities are closer together.

Differentiating (A.19), we can show that consumer surplus can either increase or decrease in the level of the higher quality. When the quality of the superior product increases, the second effect works in the opposite direction since now the two qualities 
become further apart. The total effect on consumer surplus from increase in the level of the higher quality is,

$$
\frac{\partial C S}{\partial q^{H}}=\frac{q^{H}\left(2 q^{H}+q^{L}\right)\left(4 q^{H}-5 q^{L}\right)}{\left(4 q^{H}-q^{L}\right)^{3}} \gtreqless 0 \Leftrightarrow q^{H} \gtreqless \frac{5}{4} q^{L}
$$

If the two qualities are initially sufficiently close, there is significant competition to begin with and the loss in consumer surplus from the reduction in competition outweighs any gain from the availability of a better product. On the other hand, if the two qualities are so far apart that there is little competition to begin with, the gain from a better product offsets the negative effect from further reduction in competition.

From the two partial derivatives, we attain the slope of the iso-consumer surplus curves in the $q^{H}-q^{L}$ space,

$$
\left.\frac{d q^{H}}{d q^{L}}\right|_{d C S=0}=-\frac{q^{H}\left(28 q^{H}+5 q^{L}\right)}{2\left(2 q^{H}+q^{L}\right)\left(4 q^{H}-5 q^{L}\right)} \gtreqless 0 \Leftrightarrow q^{H} \lesseqgtr \frac{5}{4} q^{L} .
$$

Without loss of generality, consider the region where $q_{1}>q_{2}$, so $q^{H}=q_{1}$ and $q^{L}=q_{2}$. At any point in the region $q_{1}>5 q_{2} / 4$ a decrease in quality of either firm's product lowers consumer surplus. In the region $q_{1}<5 q_{2} / 4$ a decrease in the lower firm's quality also reduces consumer surplus. However, in this region a decrease in the higher firm's quality increases consumer surplus, since the benefit from increasing competition outweighs the loss from better product.

It is straightforward to show that $\partial \Pi_{2}\left(q_{1}, q_{2}\right) / \partial q_{2}<0$ along $q_{1}=5 q_{2} / 4$, for all $k$. This implies that firm 2's best response correspondence, $\beta_{2}$ must lie to the left of this line. Thus, the equilibria are in the region where the iso-consumer surplus curves are downward sloping. Consumer surplus decreases as one moves southwest, and thus 
consumer surplus at $E^{J}$ is less than at $E_{1}^{U}$.

Calculation of Aggregate Profit and Social Surplus

\begin{tabular}{|l|c|c|}
\hline & U.S. Patent Rules, $E_{1}^{U}$ & Japanese Patent Rules, $E^{J}$ \\
\hline$\Pi_{1}$ & $0.012219 / k$ & $0.012235 / k$ \\
\hline$\Pi_{2}$ & $0.000764 / k$ & $0.000757 / k$ \\
\hline$\Pi_{1}+\Pi_{2}$ & $0.012983 / k$ & $0.012992 / k$ \\
\hline Consumer Surplus & $0.021609 / k$ & $0.021016 / k$ \\
\hline Social Surplus & $0.034592 / k$ & $0.034008 / k$ \\
\hline
\end{tabular}




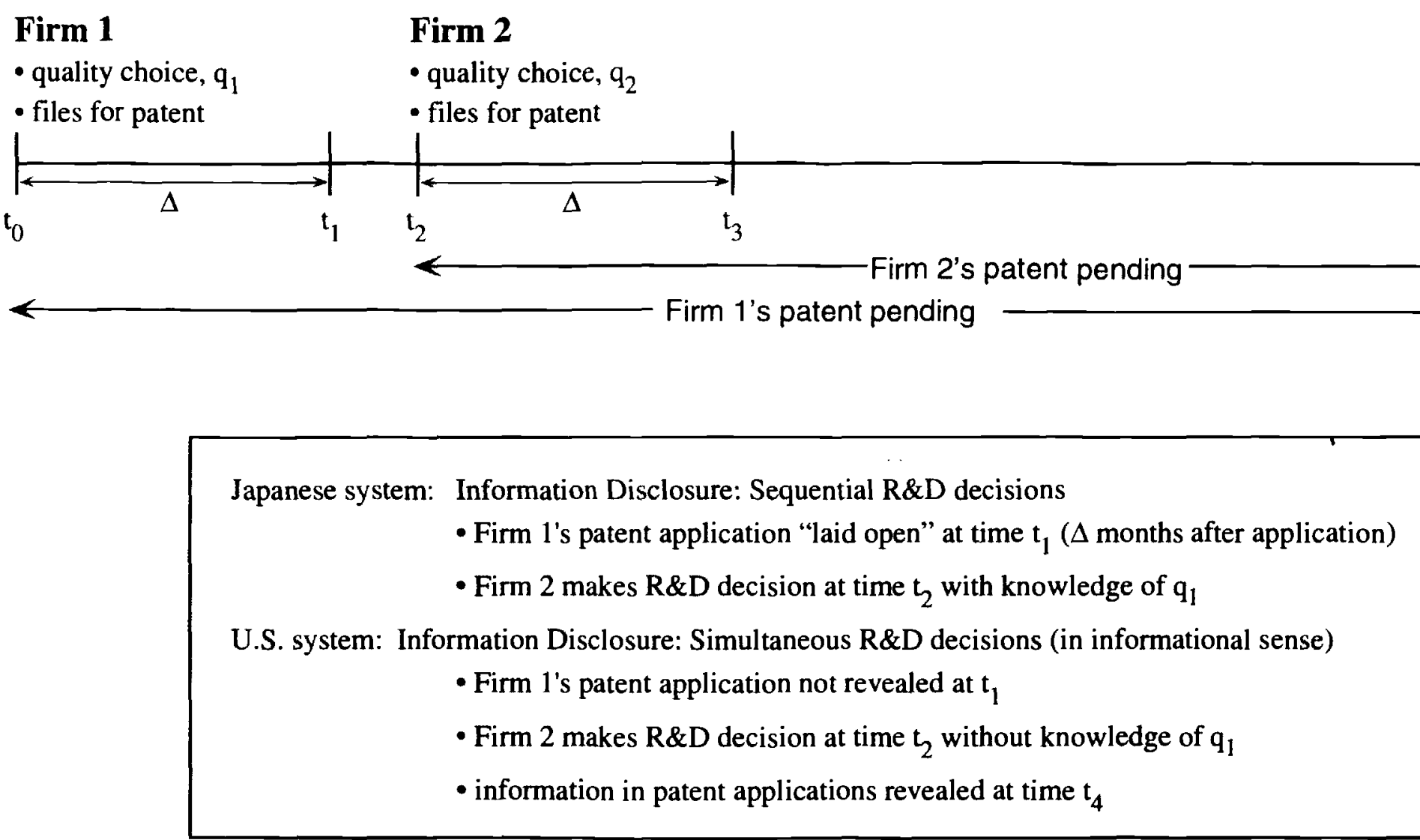

\section{Figure 1: The Timing of Information Disclosure}




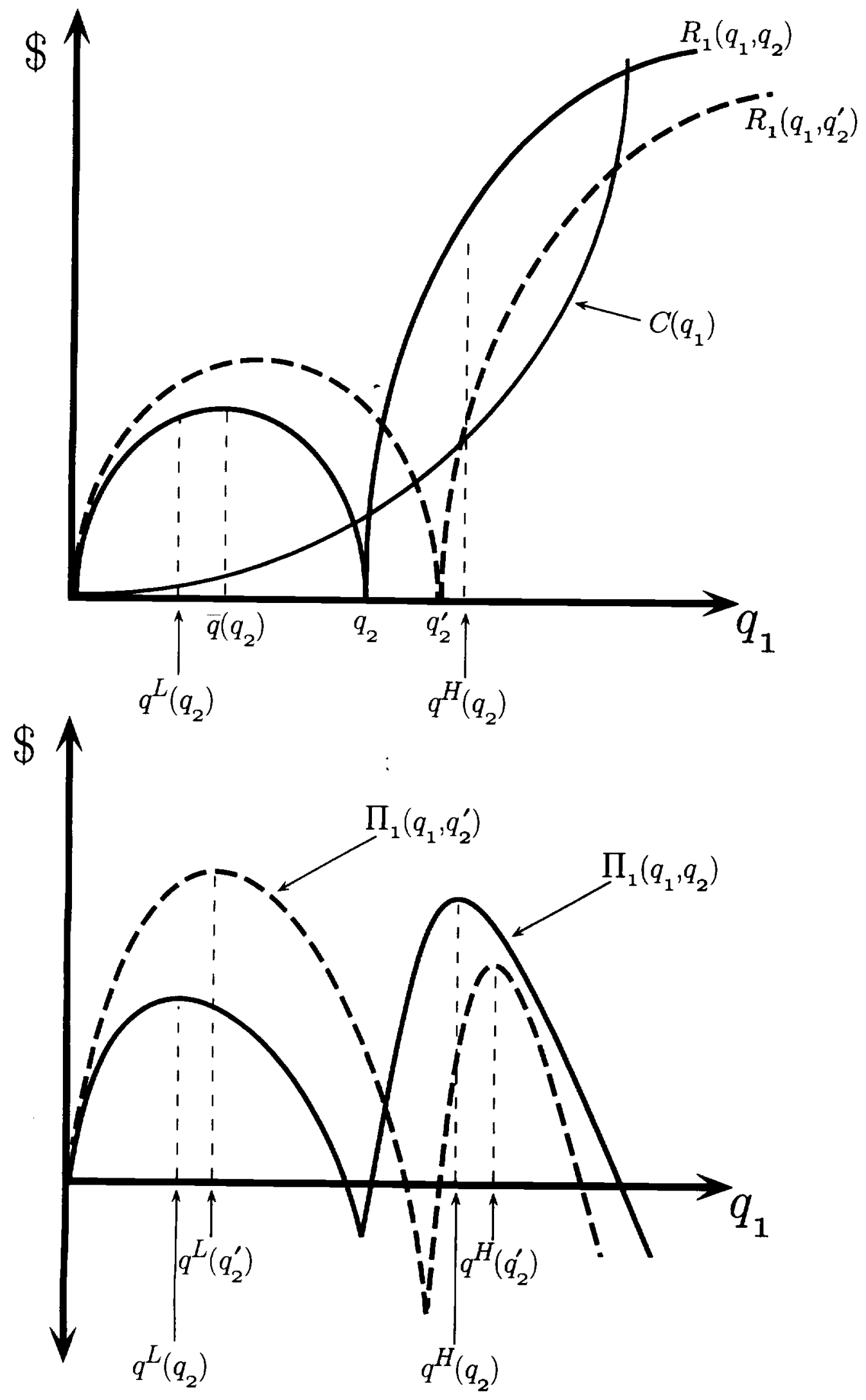

Figure 2 


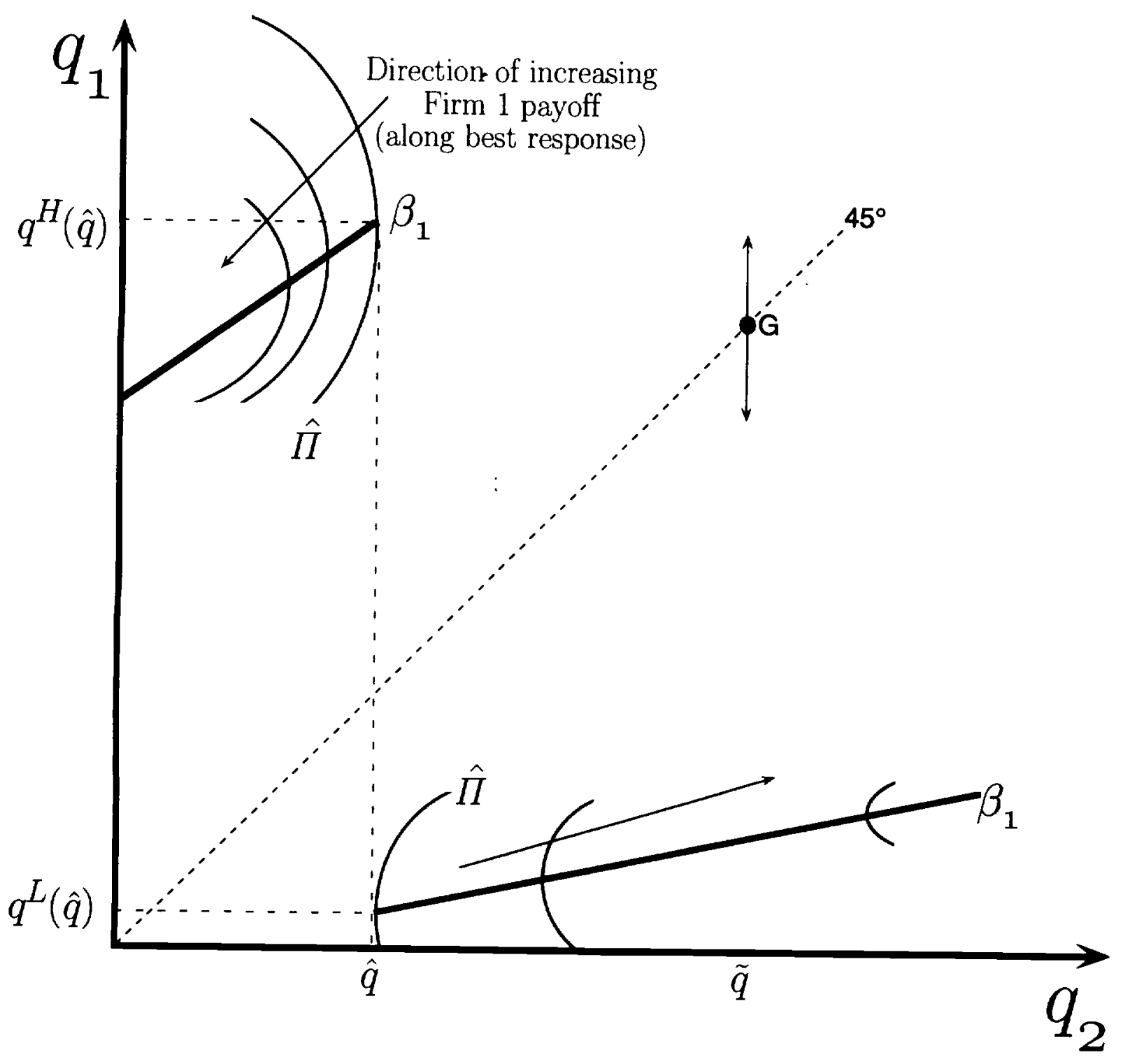

Figure 3 


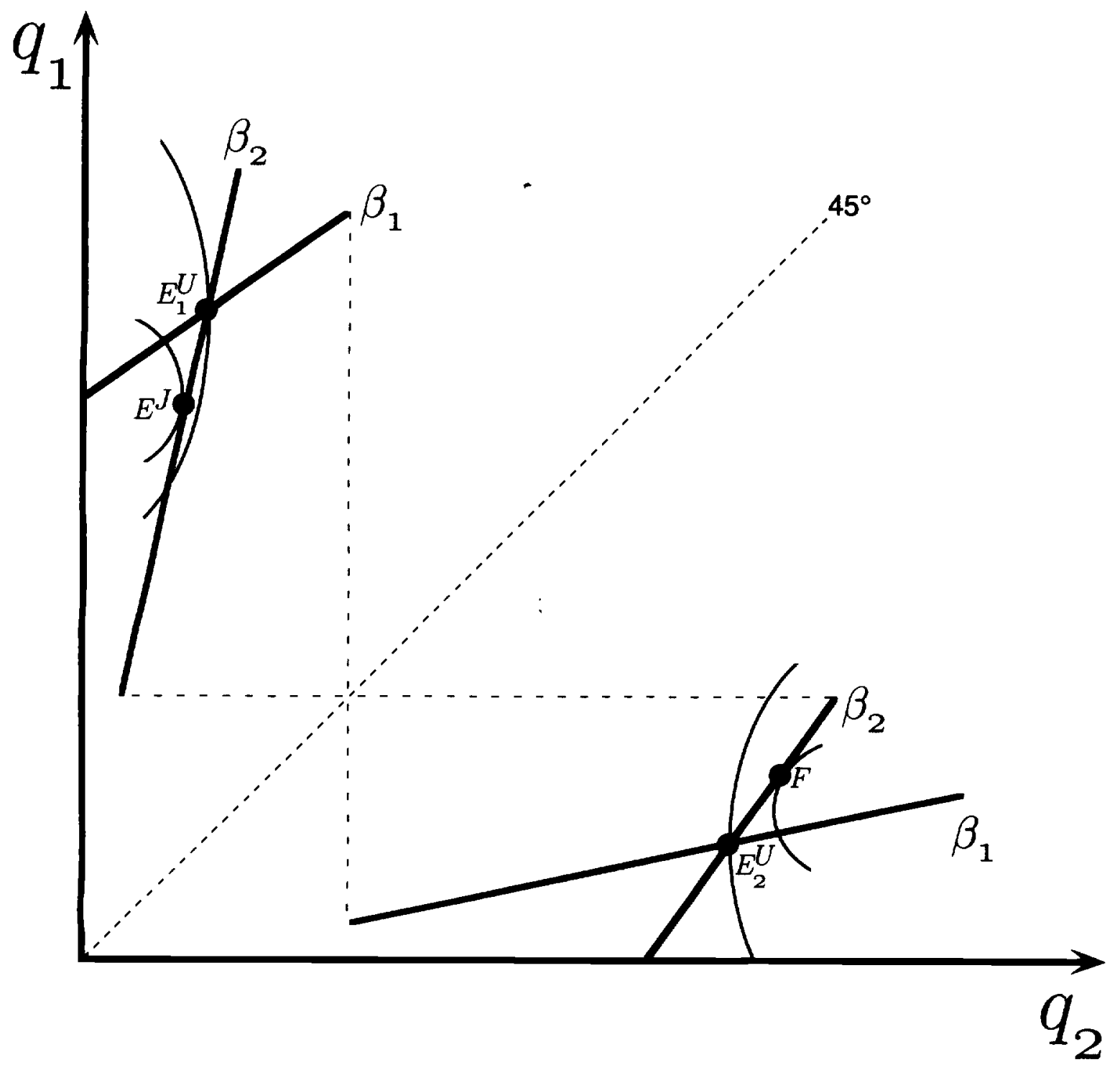

Figure 4 